\title{
A STUDY OF THE RELIABILITY AND VALIDITY OF THE TURKISH VERSION OF THE WALTER REED VISUAL ASSESSMENT SCALE IN ADOLESCENTS WITH IDIOPATHIC SCOLIOSIS
}

\author{
๑ Illker ÇOLAK'1, ๑ Tuğba KURU ÇOLAK² \\ ${ }^{1}$ Dr. Lütfi Kırdar Kartal Training and Research Hospital, Clinic of Orthopaedics and Traumatology, Istanbul, Turkey \\ ${ }^{2}$ Marmara University Faculty of Health Sciences, Department of Physiotherapy and Rehabilitation, Istanbul, Turkey
}

\begin{abstract}
Objective: The Walter Reed Visual Assessment Scale (WRVAS) was developed to evaluate deformity perception in patients with idiopathic scoliosis. The WRVAS has been shown to have a strong internal reliability and a high validity. This study aimed to determine the reliability and validity of the Turkish version of the WRVAS (WRVAS-TR).

Materials and Methods: The translated Turkish version of the WRVAS was administered twice to 58 patients in a one-week interval to test the reliability of the scale. Cronbach's alpha coefficient was used to assess the internal consistency. Convergent validity was assessed by analysing the correlation between the WRVAS-TR and the Scoliosis Research Society-22 (SRS-22) scales.

Results: The mean age of the patients was 12.8 years, maximum Cobb angle was $32.1^{\circ}$ and maximum angle of trunk rotation was $9.9^{\circ}$. The intraclass correlation coefficient for the item-total score was 0.906 ( $p<0.001)$. The Cronbach's alpha coefficient for all the seven items was 0.783. Self-image scores of the SRS- 22 had significantly negative correlations with the $1^{\text {st }}(p=0.03)$ and $4^{\text {th }}(p=0.003)$ questions and the total WRVAS-TR scores $(\mathrm{p}=0.01)$.

Conclusion: Improving the aesthetic appearance has been identified as one of the main goals of scoliosis management. For adolescents especially, cosmetic appearance is more important than the angles measured on X-rays. WRVAS-TR test-re-test results showed high reliability and significantly negative correlations with self-image scores of the SRS-22.

Keywords: Adolescent idiopathic scoliosis, body image, self-perception
\end{abstract}

\section{INTRODUCTION}

Over the last 20 years, treatment goals, patient expectations and the criteria for evaluating the treatment outcomes of adolescent idiopathic scoliosis have changed. Aesthetic appearance is one of these evaluation criteria and physical deformity as perceived by adolescents is considered as one of the most important dimensions of idiopathic scoliosis ${ }^{(1,2)}$.

Improving the aesthetic appearance has been identified as one of the main goals of scoliosis management according to the consensus reached by the Society on Scoliosis Orthopaedic and Rehabilitation Treatment professionals ${ }^{(2)}$. Moreover, perceived body image in idiopathic scoliosis is an important factor affecting the quality of life ${ }^{(3)}$. School screenings performed in different cities across Turkey showed that the frequency of idiopathic scoliosis varied between $0.47 \%$ and $0.49 \%(4,5)$. Despite the high incidence of idiopathic scoliosis, there is unfortunately no instrument in the Turkish language to assess the deformity perceptions of these adolescents.

The Walter Reed Visual Assessment scale (WRVAS) has been shown to be a valid scale to evaluate the cosmetic deformity perception in patients with scoliosis ${ }^{(1,6)}$. Sanders et al. ${ }^{(1)}$ suggested that there is a strong correlation between curve magnitude and the WRVAS and that curves of $\geqslant 30^{\circ}$ can be clearly differentiated from lesser curves.

With the aim of making the WRVAS available for Turkish patients, the instrument was translated into Turkish, and the reliability and validity tests were conducted on adolescents with idiopathic scoliosis.

\section{MATERIALS AND METHODS}

This study included adolescents who were admitted to our institution and diagnosed with idiopathic scoliosis by a physician between September 2019 and December 2019. The

Address for Correspondence: Illker Çolak, Dr. Lütfi Kırdar Kartal Training and Research Hospital, Clinic of Orthopaedics and Traumatology, İstanbul, Turkey Phone: +90 5369530716 E-mail: drilkercolak@hotmail.com Received: 31.05.2020 Accepted: 26.07.2020

ORCID ID: orcid.org/0000-0003-2960-2825 
study was approved by the institutional review board and was conducted in compliance with the Helsinki Declaration. Patients and parents were informed about the study and a written consent obtained.

The exclusion criteria were as follows: non-idiopathic scoliosis, a previous spinal surgery, accompanying mental disorders, muscular, neurological or rheumatic diseases. The Cobb angle and Risser sign were assessed on the anteroposterior radiographs. The angle of trunk rotation (ATR) was measured with a Bunnell Scoliometer ${ }^{\mathrm{TM}}$ and the readings were obtained in a standing position with forward bending.

The WRVAS is an instrument that was developed by Dr. Sanders to assess the subjective perception of physical deformity in patients with idiopathic scoliosis ${ }^{(1)}$. The internal consistency of the instrument has been found to be excellent and high correlations with the curve magnitude have been reported in previous studies ${ }^{(1,6)}$. This scale includes seven items with figures representing different aspects of the spinal deformity: spinal deformity, rib prominence, lumbar prominence, thoracic deformity, trunk imbalance, shoulder asymmetry and scapular asymmetry. The figures are scored from minimum (1, no deformity) to maximum (5, severe deformity) and summed up to yield a total score (minimum: 5 points, maximum: 35 points). It can be completed by the patient, the patient's family or the clinician. It is recommended for clinical assessment because the application and scoring are very simple $e^{(1,6,7)}$.

Permission to translate was obtained from Sanders et al. ${ }^{(1)}$ and the WRVAS was then translated into Turkish. The translation process was performed according to the Consensus-based Standards for the selection of health status Measurement Instruments criteria and the previously described guidelines ${ }^{(8,9)}$. The English version of the scale was translated into Turkish independently by two academicians with an advanced English language level. The translations were reviewed by the same persons and a consensus text was obtained. The Turkish version agreed upon was translated back into English by a physiotherapist and a PhD student with an advanced English language level. The translators and researchers compared the original, translated English versions and the consensus version, necessary corrections were made and the final Turkish version was produced (Figure 1). The sample instrument with Turkish headings was administered to 10 healthy adolescents who presented at the clinic to test its comprehensibility. To estimate the test-re-test reliability, the scale was re-administered to the same patients after a one-week interval.

The Scoliosis Research Society-22 (SRS-22) questionnaire is a patient-reported outcome instrument for the assessment of the health-related quality of life of patients with idiopathic scoliosis. It was then modified by Asher et al. ${ }^{(10)}$ (SRS-22r), and a validated Turkish version was made available ${ }^{(11)}$. The SRS22 consists of 20 questions that represent four dimensions: function/activity, pain, self-image and mental health and two additional questions about patient satisfaction with the

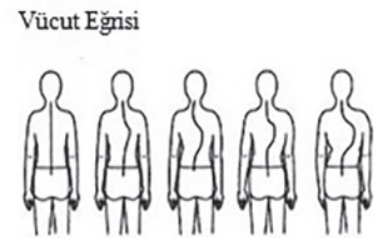

Kaburga Çıkıntısı

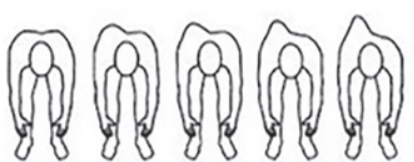

Bel Çıkıntısı
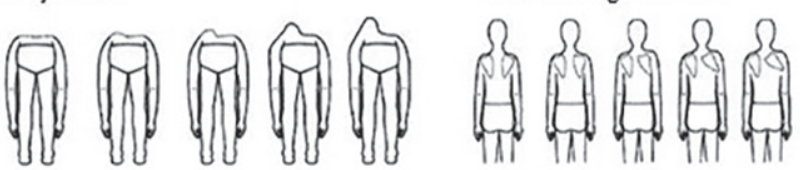

Baş-Kaburgalar-Leğen Kemiğ

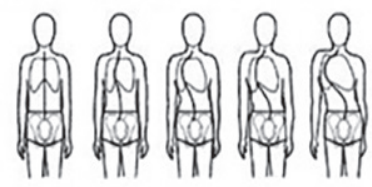

Figure 1. Turkish version of the Walter Reed Visual Assessment Scale

treatment (these questions were not included in the present study). Each item and domain is scored from 1 (worst) to 5 (best), with higher scores indicating better outcomes ${ }^{(10)}$.

\section{Statistical Analysis}

Cronbach's alpha coefficient was estimated to assess the scale's internal consistency. The intraclass correlation coefficient was calculated for each item of the questionnaire. The convergent validity was analysed by measuring the correlation (Spearman's test) between the WRVAS-TR and the SRS-22 scales.

\section{RESULTS}

A total of 58 adolescents (51 females) with a mean age of $12.8 \pm 1.3$ years (range; $10-16$ years) and mean Risser sign of 1.4 (range; 0-3) were included in this study. The maximum Cobb angle was $32.1 \pm 8.6^{\circ}$ (range; 20 to 60 ) and maximum ATR was $9.9 \pm 4.4^{\circ}$ (range; $3-20$ ).

No floor and ceiling effects were detected for the total WRVASTR score (Table 1). The mean scale score was 13.5 \pm 3.4 (range; $7-21$ ) in the first assessment and 13.4 \pm 3.6 (range; 7-21) in the second assessment (Table 2). Test-re-test correlation coefficients for the item-total score was $0.906(p<0.001)$. The Cronbach's alpha coefficient was 0.783 .

Correlation analysis of the WRVAS-TR questions and SRS-22 sub and total scores (Table 3) showed that self-image scores of the SRS-22 had significantly negative correlations (low degree) with the $1^{\text {st }}(p=0.03)$ and $4^{\text {th }}(p=0.003)$ questions and total 
scores of WRVAS-TR $(\mathrm{p}=0.01)$.

\section{DISCUSSION}

The results of this study showed that WRVAS as a high reliability for Turkish patients. The total WRVAS scores had a negative correlation with the SRS-22 self-image subscores.

The floor and ceiling effect analyses showed that the ceiling effect was notably low (1.7\% to $6.9 \%$ ), whereas the floor effect

Table 1. Floor and ceiling effects of the WRVAS questions

\begin{tabular}{lll}
\hline & $\begin{array}{l}\text { Patients with a } \\
\text { minimum score } \\
(\%)\end{array}$ & $\begin{array}{l}\text { Patients with a } \\
\text { maximum score (\%) }\end{array}$ \\
\hline WRVAS1 & 20.7 & 5.2 \\
\hline WRVAS2 & 31 & 6.9 \\
\hline WRVAS3 & 31 & 3.4 \\
\hline WRVAS4 & 17.2 & 1.7 \\
\hline WRVAS5 & 34.5 & 3.4 \\
\hline WRVAS6 & 29.3 & 1.7 \\
\hline WRVAS7 & 32.8 & 1.7 \\
\hline $\begin{array}{l}\text { WRVAS } \\
\text { (Total) }\end{array}$ & 1.7 & 1.7 \\
\hline WVAS: & &
\end{tabular}

WRVAS: The Walter Reed Visual Assessment Scale was somewhat higher (1.7\% to $34.5 \%)$. These results were similar to those of Pineda et al. ${ }^{(6)}$.

The WRVAS questionnaire was adapted linguistically and the reliability and validity for Turkish patients were evaluated in this study. Cronbach's alpha coefficient and item-total correlation are calculated to determine the reliability of a survey instrument. Cronbach's alpha values of 0.70 or higher indicate a good correlation between items ${ }^{(12)}$. In the present study, the Cronbach's alpha coefficient was 0.783 . Internal consistency of the Turkish version of the WRVAS showed good reliability and the test-re-test results demonstrated high reliability. Pineda et al. ${ }^{(6)}$ reported excellent Cronbach's alpha coefficient of the scale's English version (0.9). However, as no other study had investigated the validity of the WRVAS in a different language, comparisons of the test-re-test correlation and Cronbach's alpha coefficients of the WRVAS-TR could not be made.

Convergent validity shows the relationship between two measures that assess the same construct. In this study, the convergent validity of the WRVAS-TR was assessed by the correlation analyses between the Turkish versions of the SRS-22 sub and total scores and the WRVAS items. Significant positive correlations were determined between the $1^{\text {st }}$ and $4^{\text {th }}$ questions and the total scores of the Turkish version of the WRVAS and SRS-22 self-image subscores. Pineda et al.(6) showed a highly

Table 2. Intraclass correlation coefficient for test-re-test reliability

\begin{tabular}{llll}
\hline & First assessment & Second assessment & ICC \\
\hline WRVAS1 & $2.1 \pm 0.8$ & $2.0 \pm 0.7$ & $0.665(p<0.001)$ \\
\hline WRVAS2 & $1.7 \pm 0.5$ & $1.7 \pm 0.6$ & $0.589(p<0.001)$ \\
\hline WRVAS3 & $1.8 \pm 0.7$ & $1.8 \pm 0.6$ & $0.716(p<0.001)$ \\
\hline WRVAS4 & $1.9 \pm 0.5$ & $1.9 \pm 0.6$ & $0.677(p<0.001)$ \\
\hline WRVAS5 & $2.0 \pm 0.9$ & $2.0 \pm 0.8$ & $0.818(p<0.001)$ \\
\hline WRVAS6 & $1.9 \pm 0.7$ & $1.8 \pm 0.6$ & $0.680(p<0.001)$ \\
\hline WRVAS7 & $1.9 \pm 0.8$ & $1.9 \pm 0.8$ & $0.819(p<0.001)$ \\
\hline $\begin{array}{l}\text { WRVAS } \\
\text { (Total) }\end{array}$ & $13.5 \pm 3.4$ & $13.4 \pm 3.6$ & $0.906(p<0.001)$
\end{tabular}

ICC: Intraclass correlation coefficient, WRVAS: The Walter Reed Visual Assessment Scale

Table 3. Correlation coefficients between the WRVAS questions and SRS-22 scales

\begin{tabular}{llllll}
\hline & Function & Pain & Self-image & Mental health & SRS-22 (Total) \\
\hline WRVAS1 & -0.067 & 0.019 & $-0.285^{* *}$ & -0.157 & -0.137 \\
\hline WRVAS2 & 0.008 & 0.134 & -0.198 & -0.015 & -0.062 \\
\hline WRVAS3 & 0.016 & 0.227 & -0.247 & -0.064 & 0.004 \\
\hline WRVAS4 & -0.210 & 0.048 & $-0.383^{* *}$ & $-0.286^{* *}$ & $-0.290^{* *}$ \\
\hline WRVAS5 & -0.025 & 0.185 & -0.212 & -0.123 & -0.023 \\
\hline WRVAS6 & -0.008 & 0.000 & -0.214 & -0.136 & -0.096 \\
\hline WRVAS7 & -0.082 & -0.114 & -0.238 & -0.195 & $-0.265^{* *}$ \\
\hline $\begin{array}{l}\text { WRVAS } \\
\text { (Total) }\end{array}$ & -0.080 & 0.109 & $-0.337^{* *}$ & -0.195 & -0.157
\end{tabular}

WRVAS: The Walter Reed Visual Assessment Scale, SRS-22: The Scoliosis Research Society-22 ${ }^{* *}: p<0.05$ 
significant correlation between the WRVAS and Cobb angle and a significant correlation between WRVAS and the SRS-22 self-image score in patients with idiopathic scoliosis having a mean age of 19.4 years. A Korean study reported a positive correlation (0.248) between the WRVAS score and the SRS-22 score in females with idiopathic scoliosis, and the mean age of the patients was 14.9 years ${ }^{(13)}$.

Some doubts have been raised about the validity of the WRVAS drawings, as the scores for some deformity-related items do not correlate with the radiological values ${ }^{(14)}$. Moreover, its face validity has been called into question because of the unrealistic curves in the drawings. Mulcahey et al. ${ }^{(15)}$ recently reported that adolescents have problems completing the questionnaire, due to difficulties in comprehending the drawings and reading the questions. Our clinical experience and observations suggest that adolescents with idiopathic scoliosis have no difficulty in understanding the questions, although they tend to have perceptions only of midline changes and are not aware of shoulder, waist and pelvis asymmetry or posterior rib hump size. It has been shown that scoliosis patients have a poorer perception of body image and brain responsiveness during visual vertical perception in comparison to healthy control groups $^{(16,17)}$. The application of specific exercises in front of a mirror, providing information regarding the spine and scoliosis and evaluating $\mathrm{X}$-rays together can improve body and deformity perception. However, the efficacy of treatment methods on the construct validity of WRVAS was not evaluated in this study. Bago et al.(7) Reported that there is a discrepancy between the WRVAS item figures and what the patient "sees in the mirror". The figures' scores appear to correspond more with the subjective impression that patients have of their spine ${ }^{(7)}$. As patients do not usually see their own back, this impression is mainly based on the spinal $X$-rays. In addition, the scale mostly assesses the thoracic area deformity, while lumbar deformity, including both flank prominence and waist asymmetry, is poorly represented. Another drawback is that the WRVAS symbolises the deformities in only one direction ${ }^{(7)}$.

\section{Study Limitations}

A limitation of this study was that no other means of evaluating the body image or deformity perception were applied. Future studies should investigate the effect of different treatment modalities, age groups, Cobb and hump magnitude and sociocultural characteristics on deformity perception.

\section{CONCLUSION}

Aesthetic appearance improvement has been identified as one of the basic goals of scoliosis treatment and the perceived body image is also an important factor affecting the quality of life ${ }^{(1,2)}$. The WRVAS-TR test-re-test results showed high reliability and significant negative correlations between the self-image scores of the SRS-22. For adolescents especially, cosmetic appearance is more important than the angles measured on X-rays.

\section{Ethics}

Ethics Committee Approval: The ethics approval for the study was obtained from the Ethics Committee of Marmara University (26.09.2019/93).

Informed Consent: Informed consent was obtained from patients.

Peer-review: Externally peer-reviewed.

\section{Authorship Contributions}

Concept: I.Ç., T.K.Ç., Design: I.Ç., T.K.Ç., Data Collection or Processing: I.Ç., T.K.Ç., Analysis or Interpretation: T.K.Ç., Literature Search: I.Ç., T.K.Ç., Writing: I.Ç., T.K.Ç.

Conflict of Interest: No conflict of interest was declared by the authors.

Financial Disclosure: The authors declared that this study received no financial support.

\section{REFERENCES}

1. Sanders JO, Polly DW, Cats-Baril W, Jones JA, Lenke LG, O'Brien MF, et al. Analysis of patient and parent assessment of deformity in idiopathic scoliosis using the Walter- Reed Visual Assessment Scale. Spine. 2003;28:2158-63.

2. Negrini S, Grivas TB, Kotwicki T, Maruyama T, Rigo M, Weiss HR. Why do we treat adolescent idiopathic scoliosis? What we want to obtain and to avoid for our patients. SOSORT 2005 Consensus paper. Scoliosis. 2006; 1:4.

3. Tones M, Moss N, Polly DW. A review of quality of life and psychosocial issues in scoliosis. Spine. 2006;31:3027-38.

4. Çilli K, Tezeren G, Taş T, Bulut O, Öztürk H, Öztemur Z, et al. School screening for scoliosis in Sivas, Turkey. Acta Orthop Traumatol Turc. 2009;43:426-30.

5. Çolak TK, Apti A, Dereli EE, Özdinçler AR, Çolak I. Scoliosis screening results of primary school students (11-15 years old group) in the west side of Istanbul. JPST. 2015;27:2797-801.

6. Pineda S, Bago J, Climent JM, Gilperez C. Validity of the Walter Reed Visual Assessment Scale to measure subjective perception of spine deformity in patients with idiopathic scoliosis. Scoliosis. 2006;1:18.

7. Bago J, Climent JM, Pineda S, Gilperez C. Further evaluation of the Walter Reed Visual Assessment Scale: correlation with curve pattern and radiological deformity. Scoliosis. 2007;2:12.

8. Beaton DE, Bombardier C, Guillemin F, Ferraz MB. Guidelines for the process of cross-cultural adaptation of self-report measures. Spine (Phila Pa 1976). 2000;25:3186-91.

9. Mokkink LB, Terwee CB, Patrick DL, Alonso J, Stratford PW, Kno $\mathrm{DL}$, et al. The COSMIN checklist for assessing the methodological quality of studies on measurement properties of health status measurement instruments: an international Delphi study. Qual Life Res. 2010;19:539-49.

10. Asher M, Min Lai S, Burton D, Manna B. Scoliosis research society-22 patient questionnaire: responsiveness to change associated with surgical treatment. Spine (Phila Pa 1976). 2003;28:70-3.

11. Alanay A, Cil A, Berk H, Acaroglu RE, Yazici M, Akcali O, et al. Reliability and validity of adapted Turkish Version of Scoliosis Research Society-22 (SRS-22) questionnaire. Spine (Phila Pa 1976). 2005;30:2464-8.

12. Bland JM, Altman DG. Cronbach's alpha. BMJ. 1997;314:572.

13. Jung J, Park M, Lee K, Kim H, Lee S, Goo B. The Correlation between Walter Reed Visual Analogue Scale (WRVAS) and Scoliosis Research Society-22 (SRS-22) Questionnaire for Idiopathic Scoliosis. J Korean Soc Phys Med. 2009;4:31-41. 
14. Bago J, Climent JM, Pineda S, Gilperez C. Further evaluation of the Walter Reed Visual Assessment Scale: correlation with curve pattern and radiological deformity. Scoliosis. 2007;2:12.

15. Mulcahey MJ, Chafetz RS, Santangelo AM, Costello K, Merenda LA, Calhoun C, et al. Cognitive testing of the spinal appearance questionnaire with typically developing youth and youth with idiopathic scoliosis. J Pediatr Orthop. 2011;31:661-7.
16. Sapountzi-Krepia DS, Valavanis J, Panteleakis GP, Zangana DT, Vlachojiannis PC, Sapkas GS. Perceptions of body image, happiness and satisfaction in adolescents wearing a Boston brace for scoliosis treatment. J Adv Nurs. 2001;35:683-90.

17. Akçay B. Investigation of the efficiency of three dimensional scoliosis exercises and balance-coordination exercises in the conservative treatment of adolescent idiopathic scoliosis patients. 2017, PhD Thesis. 